\title{
New electronic health record blueprint to call for increased patient participation
}

Published at www.cmaj.ca on May 20

$\mathrm{A}$ look into the future of Canadian health care by Canada's top electronic health information strategist suggests physicians and patients alike should prepare for futuristic-sounding scenarios in which clinical care is increasingly influenced by computerized decision-making of the sort first seen in the 1968 movie 2001: A Space Odyssey.

In late April, Ron Parker, group director of solutions projects for Canada Health Infoway Inc., previewed his new national electronic health record (EHR) blueprint before more than 200 EHR experts at a conference in Montréal, Quebec. The conference was organized by Infoway, a federal agency that has received $\$ 2.1$ billion since 2001 to build a national health "infostructure."

The blueprint, scheduled for publication in September, will be based on a vision in which computers will be used to "materially affect the behaviour of the patient and the provider," Parker said, while enabling patients to "actively participate in events affecting their health."

In this "new world," Parker enthused, "interoperable" computer systems capable of communicating with multiple health care facilities and jurisdictions that rely on computerized medical taxonomies will serve as "clinical support" mechanisms for physicians and other care providers.

"The implications of what we're proposing are pretty significant administratively and from a clinical practice perspective," says Parker, who is responsible for the strategic development and execution of federal electronic health information systems architecture, standards and security. Parker was the lead architect for Infoway's current EHR solution blueprint, which was first outlined in 2003.

Patients, too, can expect changes of a very futuristic sort, Parker says.

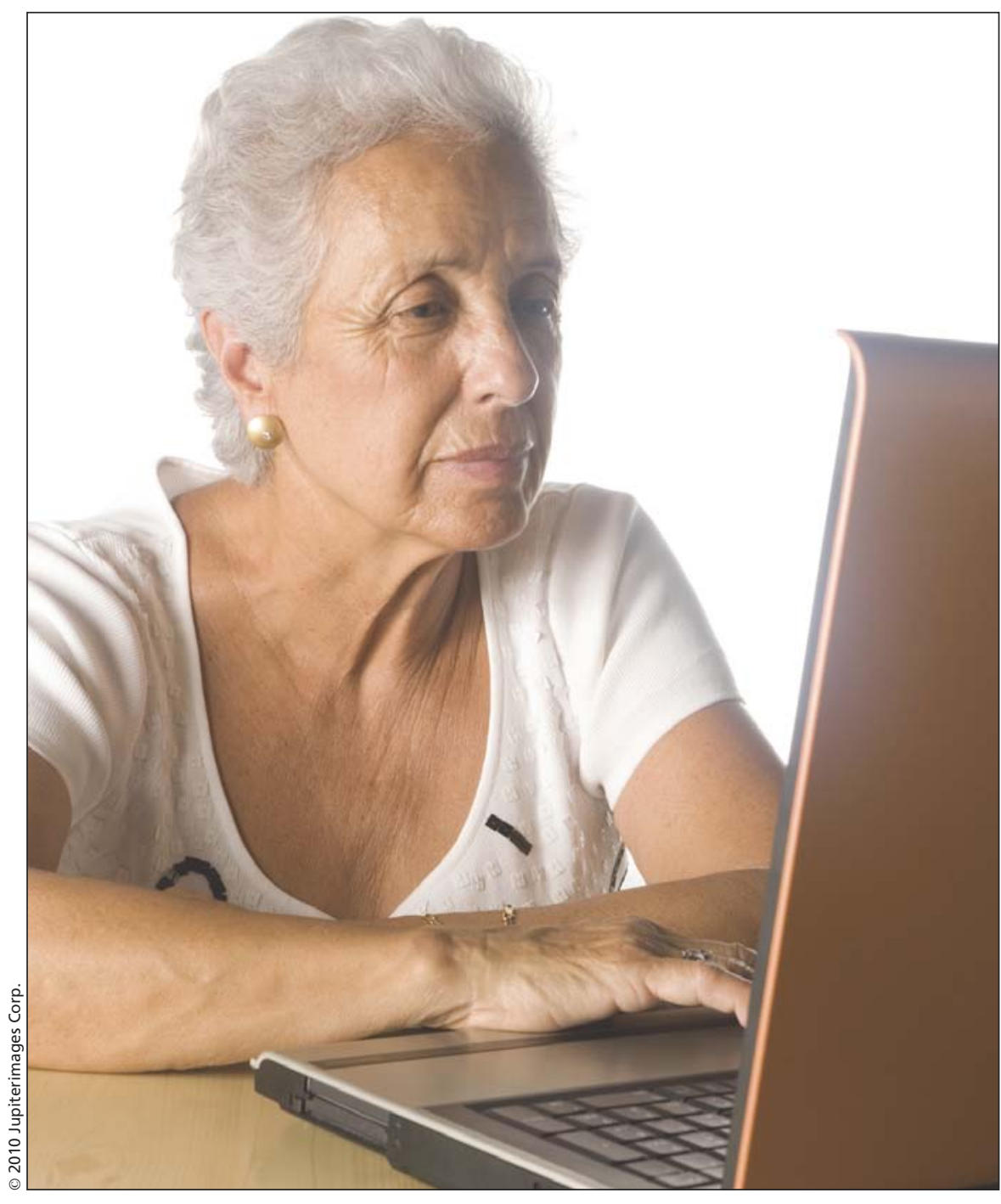

In the near future, Canadians might be able to access individualized personal health information and schedule medical appointments online.

Canadian patients are "overwhelmingly unhappy" about "the lack of continuity, the lack of having a sense of what their course of treatment will be and what that path will look like, and what will come next and where will be the key decision points where certain things need to be determined," Parker argues.

The blueprint he is now drafting envisions addressing these complaints by providing patients access to individ- ualized personal health information, as well as by allowing patients to schedule appointments online and choose from lists of facilities available for some types of treatment.

After noting that people often do their own health care research online, Parker said that patients can become better informed than their physicians. "It's a tough pill for the clinicians to swallow, because how can they possi- 
bly be aware of all of this emerging information?" he asked. "This is one of the things that we are going to attempt to address in terms of improving the provider experience."

He did not provide details on how this could be addressed. "The biggest thing that we are enabling in the future vision," Parker said, "is the capacity for the participant in the system to be more aware and to be able to adapt behaviour depending on the evidence."

Parker said the new blueprint is being developed around the objectives of "enabling and improving patient access and participation. Enabling interprofessional collaboration. Enabling integrated service delivery and enabling information for decision support and better utilization of health care services and - not a small point — for quality improvement."

Infoway previously revealed that patient self-management is part of its plans, along with automated "decision support" systems for physicians and care providers, in the document 2015: Advancing the Next Generation of Health (www2.infoway-inforoute.ca/Documents /Vision_2015_Advancing_Canadas_next _generation_of_healthcare\%5B1\%5D .pdf). But Parker offered a far more detailed picture of a brave new world for Canadian health care than has ever been publicly offered by Infoway.

In Parker's account of the coming era, clinical information added to an EHR will pass through automated decision-support "rules" to guide physician and care-giver decisions. "For example," he said. "I'm brokering an appointment and I declare that's when the appointment's going to be, and I confirm that, and that information flows up to the infostructure. We could have a business rule that looks at the interval between now and when we think that appointment is going to occur and says 'sorry, for hip replacement, which is what this intervention is intended to be, that's well outside our window'."

Within this type of computerassisted clinical decision-making process, says Parker, "best practice or whatever has been established whether it's regional or jurisdictional or by discipline - that asserts that, 'You know what? You need to know the following things.' And that content - it could be an alert, a notification - it could be, 'You know what? Now is the time to fill out this assessment tool.' It could be, 'OK, now we're in a chronic disease management pattern where we have multiple providers and now we need to coordinate a care plan'."

"Lots of different kinds of content, can be pushed back down the appointment service" by computers, says Parker, to guide the decisions expected from physicians and caregivers. "What we're talking about is elevating our capacity to be able to ... provide appropriate contextually based responses back to the provider at the point of care or back to the patient."

Parker notes that the degree of automated control over clinical decisionmaking could vary. "Trigger thresholds are defined and managed to different levels" within the new blueprint Infoway is drafting, says Parker, "by authoritative and assigned authors and requires a new type of governance." To help ensure caregiver compliance with computer prompts, in Parker's logic, "there needs to be a degree of shared governance."

In forging the new standards for automated decision-making strategies, cautions Parker, care providers will need to be permitted to override some of these rules.

While the new blueprint from Infoway will recognize that physicians and other health care providers may not warm to the presence of a governmentdesigned-and-operated HAL in their clinics, Parker believes that "interactive behaviour must be standardized." He said he was shocked after joining Infoway "to realize just how poorly information technology was used in operations in terms of supporting the business of health care."

The fix will require much stronger automation, he believes. "A system means you have feedback mechanisms.
You have information flow. You have ways of knowing how things are happening. That allows the system to be adaptive. To self-adjust. And that didn't seem to be true for health care."

But in Parker's view, creating the new world order for Canadian health care is not principally a matter of developing new technologies. "It's actually about behaviour, and it's about everyone agreeing to adhere to a particular pattern," he told participants at the Infoway conference. "That's not small. That's big." — Paul Christopher Webster, Toronto, Ont.

DOI:10.1503/cmaj.109-3265

Eighth in a series on electronic health records.

Part I: Canada's electronic health records initiative stalled by federal funding freeze (CMAJ 2010:

DOI:10.1503/cmaj.109-3183)

Part II: Ontario's plan for electronic health records is at risk, official says (CMAJ 2010: DOI:10.1503/cmaj.1093193)

Part III: Electronic health records a "strong priority" for US government (CMAJ 2010: DOI:10.1503/cmaj.1093218)

Part IV: The pocketbook impact of electronic health records: PRO (CMAJ 2010: DOI:10.1503/cmaj.109-3225)

Part V: The pocketbook impact of electronic health records: CON (CMAJ 2010: DOI:10.1503/cmaj.109-3226)

Part VI: National standards for electronic health records remain remote (CMAJ 2010: DOI:10.1503/cmaj.109-3239)

Part VII: National electronic health records initiative remains muddled, auditors say (CMAJ 2010:

DOI:10.1503/cmaj.109-3242) 